\title{
Blooms of cyanobacteria in a temperate Australian lagoon system post and prior to European settlement
}

\author{
Perran L. M. Cook ${ }^{1}$, Miles Jennings ${ }^{1}$, Daryl P. Holland ${ }^{1}$, John Beardall ${ }^{2}$, Christy Briles ${ }^{3}$, Atun Zawadzki ${ }^{4}$, \\ Phuong Doan ${ }^{5, \mathrm{a}}$, Keely Mills ${ }^{5,6}$, and Peter Gell ${ }^{5}$ \\ ${ }^{1}$ Water Studies Centre, School of Chemistry, Monash University, Clayton, VIC 3800, Australia \\ ${ }^{2}$ School of Biological Sciences, Monash University, Clayton, VIC 3800, Australia \\ ${ }^{3}$ Geography and Environmental Sciences, University of Colorado, Denver, CO 80217-3364, USA \\ ${ }^{4}$ ANSTO Institute for Environmental Research, Lucas Heights, NSW 2232, Australia \\ ${ }^{5}$ Water Research Network, Federation University Australia, Ballarat, VIC 3350, Australia \\ ${ }^{6}$ British Geological Survey, Keyworth, Nottingham, NG12 5GG, UK \\ ${ }^{a}$ now at: Faculty of Biology - Environment, The University of Da Nang, Đa Năng, Vietnam \\ Correspondence to: Perran L. M. Cook (perran.cook@monash.edu)
}

Received: 14 October 2015 - Published in Biogeosciences Discuss.: 25 November 2015

Revised: 26 May 2016 - Accepted: 1 June 2016 - Published: 22 June 2016

\begin{abstract}
Blooms of noxious $\mathrm{N}_{2}$ fixing cyanobacteria such as Nodularia spumigena are a recurring problem in some estuaries; however, the historic occurrence of such blooms in unclear in many cases. Here we report the results of a palaeoecological study on a temperate Australian lagoon system (the Gippsland Lakes) where we used stable isotopes and pigment biomarkers in dated cores as proxies for eutrophication and blooms of cyanobacteria. Pigment proxies show a clear signal, with an increase in cyanobacterial pigments (echinenone, canthaxanthin and zeaxanthin) in the period coinciding with recent blooms. Another excursion in these proxies was observed prior to the opening of an artificial entrance to the lakes in 1889, which markedly increased the salinity of the Gippsland Lakes. A coincident increase in the sediment organic-carbon content in the period prior to the opening of the artificial entrance suggests that the bottom waters of the lakes were more stratified and hypoxic, which would have led to an increase in the recycling of phosphorus. After the opening of the artificial entrance, there was $a \sim 60$ year period with low values for the cyanobacterial proxies as well as a low sediment organic-carbon content suggesting a period of low bloom activity associated with the increased salinity of the lakes. During the 1940s, the current period of re-eutrophication commenced, as indicated by a steadily increasing sediment organic-carbon content and cyanobacterial pigments. We suggest that increasing nitrogen inputs
\end{abstract}

from the catchment led to the return of hypoxia and increased phosphorus release from the sediment, which drove the reemergence of cyanobacterial blooms.

\section{Introduction}

Harmful algal blooms (HABS) are becoming increasingly prevalent throughout the world. One of the key causes of this is eutrophication of aquatic environments by excessive nutrient inputs (Conley et al., 2009). Climatological and hydrological factors are increasingly recognized as an important contributor to HABS through altered temperature and salinity regimes (Paerl and Paul, 2012). Blooms of toxic cyanobacteria such as Nodularia spumigena are particularly conspicuous in some estuaries such as the Baltic Sea, the Peel-Harvey Estuary and the Gippsland Lakes (Cook and Holland, 2012; Lukatelich and McComb, 1986; Conley et al., 2009). The most likely reasons for their dominance in these systems are (1) a long water residence time, (2) intermediate salinity ( 5-20) and (3) a high supply of phosphorus (both from the catchment and from anoxic bottom waters and sediments). As such, the frequency and occurrence of these blooms is likely to result from a strong interaction between anthropogenic nutrient loading and climatological and hydrological factors. 
In the case of the Baltic Sea, cyanobacterial blooms have occurred sporadically since the formation of the Littorina Sea 8000 years BP (Bianchi et al., 2000). The presence of cyanobacteria is most likely controlled by the extent of bottom water hypoxia, which leads to an efficient recycling of phosphorus (Funkey et al., 2014). The extent of hypoxia in the Baltic has been controlled by morphological and hydrological changes; however, the most likely control over hypoxia and cyanobacterial blooms over the past 2 millennia is the expansion and contraction of human activities (Zillen and Conley, 2010). Similarly, in the Gippsland Lakes and PeelHarvey Estuary, the frequent and intense blooms are thought to be relatively recent phenomena, with significant blooms only observed after the late 1970s (McComb and Humphries, 1992). In the Peel-Harvey Estuary, the intensity of N. spumigena blooms is strongly related to river discharge during the previous winter and spring, which delivers significant quantities of phosphorus as well as reducing the salinity of the estuary to a range favourable to $N$. spumigena growth (McComb and Humphries, 1992). The critical importance of salinity in controlling N. spumigena blooms is well illustrated in the Peel-Harvey Estuary, where a newly cut channel to the sea increased the salinity of the estuary and virtually eliminated N. spumigena blooms (Wildsmith et al., 2009).

In the Gippsland Lakes, Australia, it has been shown that $N$. spumigena bloom size is decoupled from catchment inputs owing to internal recycling of $\mathrm{P}$ driven by stratification (Cook and Holland, 2012). As such, N. spumigena blooms typically occur during wet years when stratification is highest; however, there is no relationship between catchment nutrient loads and bloom size (Cook and Holland, 2012). Nevertheless, anthropogenic activities are likely to have played a role in the occurrence of recent blooms through increased phosphorus inputs leading to increased sediment phosphorus storage as well as increased nitrogen inputs which are likely to drive increased releases of phosphorus from the sediment through increased anoxia (Cook et al., 2010). Prior to European settlement, the Gippsland Lakes were connected to the ocean by an ephemeral entrance (Bird, 1978). In 1889, a permanent artificial entrance was opened, which increased the salinity regime of the lakes (Saunders et al., 2008). There are anecdotal accounts of $N$. spumigena blooms prior to the opening of the artificial entrance, but there is no information on the relative frequency or intensity of blooms at this time. Two alternative hypotheses were tested here. (1) The fresher, less flushed and more stratified environment prior to the opening of the artificial entrance may have been more conducive to anoxia, associated sediment phosphorus release and cyanobacterial blooms than post opening. (2) Alternatively, low nutrient inputs prior to European settlement may have led to a lower incidence of hypoxia and associated cyanobacterial blooms. The aim of this study was to investigate changes in the trophic status and frequency of cyanobacterial blooms in the Gippsland Lakes before the opening of the artificial entrance up to the present day using pigment,

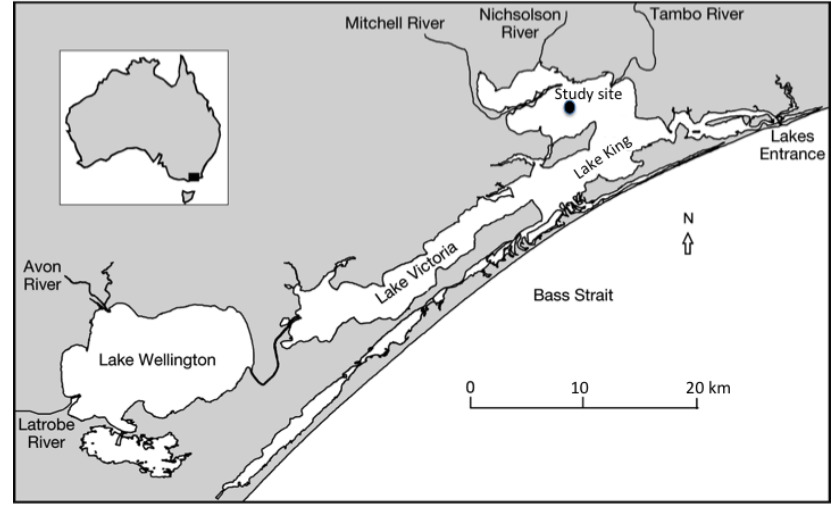

Figure 1. The Gippsland Lakes, south-eastern Australia. The study site in northern Lake King is marked with the solid circle $\left(37.875620^{\circ} \mathrm{S}, 147.757280^{\circ} \mathrm{E}\right)$.

organic matter and isotope proxies on dated cores taken from the centre of the lake system. The findings provide an important, longer-term perspective from which to frame modern management regimes within the Gippsland Lakes as well as systems modified by humans more generally.

\section{Materials and methods}

\subsection{Study site}

The Gippsland Lakes are located in south-eastern Australia, and experience a temperate climate with a water temperature range of $\sim 10-25^{\circ} \mathrm{C}$ (Fig. 1). The lakes are fed by 5 river systems including the Latrobe and Avon in the west, and the Mitchell, Tambo and Nicholson in the east. Lake Wellington in the west is a shallow basin with an average depth of $\sim 2.6 \mathrm{~m}$ and typically has a salinity $<15$. Lakes King and Victoria in the east have an average depth of $\sim 5 \mathrm{~m}$. The lakes cover an area of $356 \mathrm{~km}^{2}$, making them one of the largest estuarine systems in Australia. Maximum river flows and floods typically occur in the austral winter and spring, which reduce surface salinities to $\sim 5-15$, which then increase to $>25$ over summer in lakes King and Victoria. Lakes King and Victoria are typically salinity stratified, with bottom water salinities of $\sim 30-35$, and during intense stratification following high river flow, the bottom waters of lakes King and Victoria may become anoxic. Winter and spring inflows typically lead to blooms of diatoms and dinoflagellates, and since 1987, periodic blooms of Nodularia spumigena have occurred in Lake King during late spring and summer when surface water salinities are 9-20 (Cook and Holland, 2012). Previous studies have shown that these blooms are phosphorus limited, that they are sustained by high sediment phosphorus release focused in the northern basin of Lake King and that these blooms can fix significant quantities of nitrogen with a $\delta^{15} \mathrm{~N}$ of $\sim 0 \%$ (Cook and Holland, 
2012; Cook et al., 2010; Holland et al., 2012; Woodland and Cook, 2014; Woodland et al., 2013).

\subsection{Sampling}

Sediment cores were taken from Lake King north (LKN; $37.875620^{\circ} \mathrm{S}, 147.757280^{\circ} \mathrm{E}$; Fig. 1) at a water depth of $7 \mathrm{~m}$ on the 15 March 2012, which is where contemporary blooms are centred. The uppermost core, LKN1 $(0-56 \mathrm{~cm})$, was retrieved by a piston corer to collect the recent, unconsolidated sediments. This core was sectioned in the field at $0.5 \mathrm{~cm}$ intervals (contiguous), to attain a chronology to aid the identification of recent changes in the sediment. During sectioning, the core was placed in a black plastic bag to shield it from light and once sectioned, samples were rapidly placed in the dark. Subsamples (1-2g) from each section were stored in glass vials, with the rest of the sample stored in ziplock bags. All samples were kept on ice and, on returning to the laboratory, the bags were transferred to the refrigerator $\left(4^{\circ} \mathrm{C}\right)$ and the vials frozen until required for stable isotope analysis. Wet samples were kept in darkness in order to reduce light exposure that could change the sediment composition.

A second drive (LKN2) using a Russian peat corer collected a deeper, older sedimentary sequence and consisted of a series of $50 \mathrm{~cm}$ (overlapping) drives from 0 to $2.1 \mathrm{~m}$. All cores were stored in halved PVC pipes, wrapped in cling film and aluminium foil and kept cool until refrigerated in the laboratory. The cores were sectioned into $1 \mathrm{~cm}$ layers using a blade and spatula and stored in the same way as LKN1. The two sequences were correlated based on the calculated field depths, and this was validated by dating across the two sequences as described in the next section.

\subsection{Dating}

The sediment cores were dated at the Australian Nuclear Science and Technology Organisation (ANSTO) Institute for Environmental Research using the lead-210 $\left({ }^{210} \mathrm{~Pb}\right)$ dating method (Appleby, 2001). Samples were chemically processed following the methods described in Atahan et al. (2015) and analysed by alpha spectrometry to determine unsupported ${ }^{210} \mathrm{~Pb}$ activities on 13 subsamples from core LKN1 $(0-51.5 \mathrm{~cm})$ and the $42-92 \mathrm{~cm}$ LKN2 sequence. A CIC (constant initial concentration) model was used to calculate the ages of the sediment samples (Appleby, 2001). The ${ }^{210} \mathrm{~Pb}$ chronology was validated with the presence of a subsurface peak of caesium-137 $\left({ }^{137} \mathrm{Cs}\right)$, which identifies the year of 1964, due to global atmospheric nuclear weapons tests (Leslie and Hancock, 2008). ${ }^{137}$ Cs activities in eight subsamples were determined by gamma spectrometry.

\subsection{Carbon and nitrogen analysis}

Sediment from the LKN1 and LKN2 core sediment sample was analysed via mass spectroscopy for percentage of nitrogen, percentage of carbon, $\mathrm{C}_{\mathrm{org}}: \mathrm{N}, \delta^{15} \mathrm{~N}$ and $\delta^{13} \mathrm{C}_{\mathrm{org}}$.
These samples were dried at $60^{\circ} \mathrm{C}$ for $30-50 \mathrm{~h}$ and placed in $1.7 \mathrm{~mL}$ Eppendorf tubes along with Qiagen Tungsten Carbide Beads $(3 \mathrm{~mm})$; they were then shaken for $6-10 \mathrm{~min}$ at $25 \mathrm{~Hz}$ using a Retsch Mixer Mill MM 200 until a fine, homogeneous powder was produced. Samples for carbon $\left(\delta^{13} \mathrm{C}_{\mathrm{org}}\right)$ were weighed in silver capsules and placed on a hotplate (60$\left.80^{\circ} \mathrm{C}\right)$ to undergo acidification. Aliquots $(20 \mu \mathrm{L})$ of $10 \%$ $\mathrm{HCl}$ were sequentially added to capsules until no effervescence was recorded. Samples for nitrogen $\left(\delta^{15} \mathrm{~N}\right)$ analysis were weighed in tin capsules. Once each capsule was prepared, it was pinched closed and pressed into a disk using a pelletizer. Each sample was analysed on an ANCA GSL2 elemental analyser interfaced to a Hydra 20-22 continuousflow isotope ratio mass spectrometer (Sercon Ltd., UK). Stable isotope data were expressed in the delta notation $\left(\delta^{13} \mathrm{C}_{\mathrm{org}}\right.$ and $\delta^{15} \mathrm{~N}$ ) relative to the stable isotopic ratio of Vienna Pee Dee Belemnite standard $\left(R_{-}\right.$VPDB $\left.=0.0111797\right)$ and the air standard $\left(\mathrm{R} \_\right.$Air $\left.=0.0036765\right)$ for carbon and nitrogen respectively. Analytical precision was $\pm 0.1 \%$ for both $\delta^{13} \mathrm{C}_{\text {org }}$ and $\delta^{15} \mathrm{~N}(\mathrm{SD}$ for $n=5)$.

\subsection{Pigments}

Pigments were analysed at $5 \mathrm{~cm}$ intervals from 0 to $41 \mathrm{~cm}$ and every $10 \mathrm{~cm}$ through to $200 \mathrm{~cm}$ from the LKN2 core sequence. Freeze-dried sediments were extracted in pure acetone overnight and stored in the dark at $-22^{\circ} \mathrm{C}$. They were then filtered, dried and redissolved under low light conditions and then injected into a Shimadzu high-performance liquid chromatography (HPLC) system. The separation conditions were modified from Mantoura and Llewellyn (1983) and Chen et al. (2001) using a $4.6 \times 150 \mathrm{~mm}, 3 \mu \mathrm{m} \mathrm{C} 8$ (Luna, Phenomenex) column. Pigment peaks were identified by retention times and spectra and then quantified by peak areas at maximum absorbance wavelength using calibrated curves from phytoplankton pigment standards DHI (Denmark). Canthaxanthin was measured at $475 \mathrm{~nm}$, and the carotenoids lutein, zeaxanthin, diadinoxanthin, diatoxanthin and echinenone were measured at $450 \mathrm{~nm}$. The pigments zeaxanthin, echinenone and canthaxanthin were used as markers for cyanobacteria (Jeffrey and Vesk, 1997); chlorophyll $a$ was measured at $665 \mathrm{~nm}$. Concentrations are reported in micromoles $(\mu \mathrm{mol})$ of pigment relative to the organic material in the sediment measured as described above.

\subsection{Diatoms}

The core sequence was subsampled every $10 \mathrm{~cm}$ for diatom analysis from the LKN2 core. Approximately $1 \mathrm{~g}$ wetweight sediment was digested in $30 \%$ hydrogen peroxide in a beaker, on a hotplate, for up to $4 \mathrm{~h}$ (Battarbee, 1986). Following digestion, a small amount of $\mathrm{HCl}$ was added to remove any carbonates. The suspensions were washed in distilled water and left to settle overnight before decanting the supernatant (repeated four times). An aliquot of the fi- 

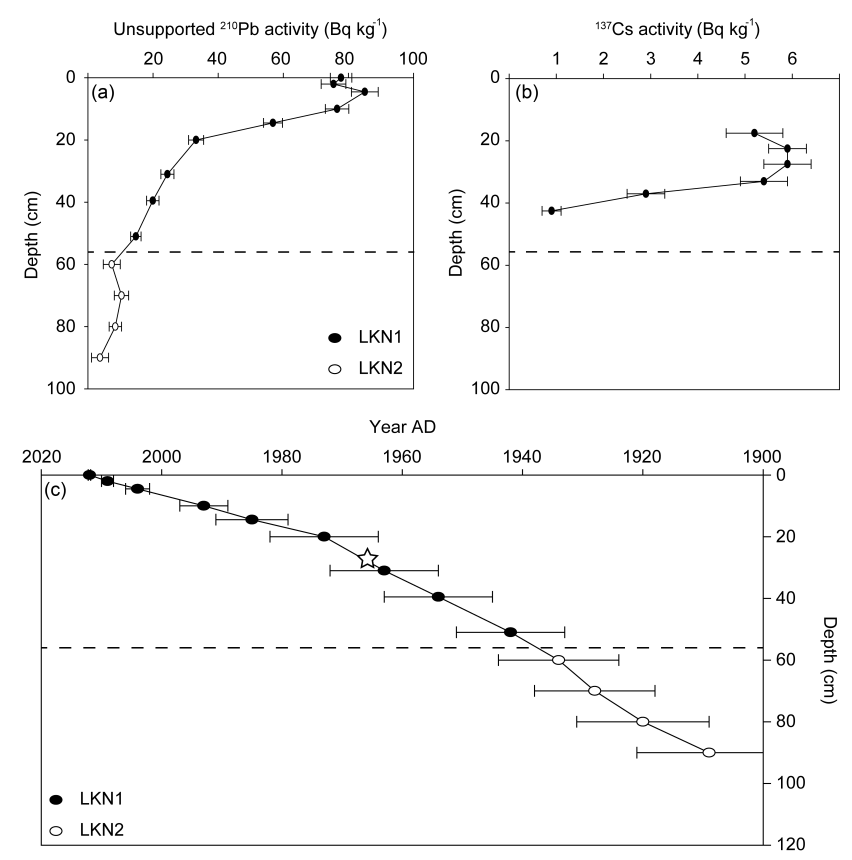

Figure 2. Unsupported ${ }^{210} \mathrm{~Pb}$ activities $\left(\mathrm{Bq} \mathrm{kg}^{-1}\right.$ sed) versus depth (a), ${ }^{137} \mathrm{Cs}$ activities $\left(\mathrm{Bq} \mathrm{kg}^{-1}\right.$ sed) versus depth (b) and the age depth model based on unsupported ${ }^{210} \mathrm{~Pb}$ values using the CIC (constant initial concentration) model (c). The star in (c) refers to the depth of the ${ }^{137}$ Cs peak activity. LKN1 and LKN2 refer to the two different cores sampled (see methods) and the horizontal dashed line demarcates the transition from core LKN1 to LKN 2.

nal suspension was placed onto a coverslip and left to dry. The coverslips were permanently mounted onto slides using Naphrax. Diatoms were identified (where possible) to species level, using a Nikon DIC microscope. Identifications were undertaken using a range of general (Krammer and Lange-Bertalot, 1986, 1988, 1991a, b) and regional (Foged, 1978; Sonneman et al., 2000) floras. A minimum of 200 valves per sample were counted, and the counts were converted to percentage data in C2 (Juggins, 2003). Where possible an ecological preference (i.e. saline, fresh, thalassic) was assigned to each species to create a habitat summary diagram. To further explore patterns in the diatom data, a detrended correspondence analysis (DCA) was carried out using Canoco 4.5.

\subsection{Charcoal}

Wet sediment ( $1 \mathrm{~mL}$ ) from the LKN2 sequence was subsampled into a $50 \mathrm{~mL}$ Falcon tube. In total, $25 \mathrm{~mL}$ of $10 \%$ tetra sodium pyrophosphate $\left(\mathrm{Na}_{4} \mathrm{P}_{2} \mathrm{O}_{7}\right)$ was added to the tube; the contents were shaken vigorously and left to sit. After $30 \mathrm{~min}, 25 \mathrm{~mL}$ of $12.5 \%$ sodium hypochlorite $(\mathrm{NaOCl})$ was added, and the tube was again shaken vigorously and then left to sit for 14-18 h. The samples were then sieved through a $250 \mu \mathrm{m}$ and then a $125 \mu \mathrm{m}$ mesh, rinsed and placed on a water-filled petri dish where the total number of charcoal and grass charcoal particles were enumerated under a dissecting microscope.

\section{Results}

\subsection{Age model}

The unsupported ${ }^{210} \mathrm{~Pb}$ activities for the King Lake core exhibit an overall decay profile with increasing depth (Fig. 2a), indicating that the core is suitable for ${ }^{210} \mathrm{~Pb}$ dating. The top $5 \mathrm{~cm}$ unsupported ${ }^{210} \mathrm{~Pb}$ activities deviate from a decay profile, which may be due to sediment mixing in the upper section of the core. Below $5 \mathrm{~cm}$ the unsupported ${ }^{210} \mathrm{~Pb}$ activities exhibit two distinct zones, where each zone follows a monotonic profile with depth, between 5-20 and $20-90 \mathrm{~cm}$. Using the CIC ${ }^{210} \mathrm{~Pb}$ dating model, the mass accumulation rate between 5 and $20 \mathrm{~cm}$ and between 20 and $90 \mathrm{~cm}$ depth was calculated to be 0.96 and $2.4 \mathrm{~g} \mathrm{~cm}^{-1} \mathrm{yr}^{-1}$ respectively. These mass accumulation rates were used to determine sediment ages between 0 and $90 \mathrm{~cm}$ core depth, which were then converted to calendar years (Fig. $2 b$ ). The ${ }^{210} \mathrm{~Pb}$ ages were validated by ${ }^{137} \mathrm{Cs}$, with the 1964 peak found in the $25-$ $30 \mathrm{~cm}$ sediment layer in the LKN1 sequence, dated to 19641969 (Fig. 2c). A further validation is the peak in charcoal abundance $\left(24 \mathrm{~mL}^{-1}\right)$ at a depth of $61 \mathrm{~cm}$ (Fig. 3), which corresponds to approximately 1937 , which is in close agreement with the date of the most widespread bushfires in the catchment in 1939. The sediment age below $90 \mathrm{~cm}$ was estimated by extrapolating the measured sedimentation rate over the depth interval 20-90 to $200 \mathrm{~cm}$. Given that sedimentation rates have increased since European settlement, this provides a minimum age for sediments below $\sim 140 \mathrm{~cm}$.

\subsection{Sediment chronology}

Three broad zones within the chronology are identified here. The delineation of the zones was based on a visual assessment of abrupt changes in the diatom and geochemical proxies as well as inflection points in DCA axis 1.

\subsubsection{Zone LK1 (c. 1810-1870, depth 130-200 cm)}

This zone covers the period of European settlement in the region. Sediment organic carbon and nitrogen content were relatively stable at 5 and $0.5 \%$ respectively and were the highest observed in the entire record (Fig. 3). Sediment $\delta^{13} \mathrm{C}$ and $\delta^{15} \mathrm{~N}$ were similarly stable at -23 and $4 \%$ respectively. Sediment $\mathrm{C}_{\text {org }}: \mathrm{N}$ ratios were $\sim 10$. Sediment pigments including diatoxanthin and cyanobacterial pigments were also sporadically high, with total cyanobacterial pigments peaking

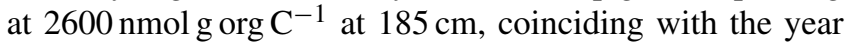
$\sim 1820$, which is the highest concentration in this record. Over this period, thalassic diatom taxa dominated, although to a much lesser extent than in the zone LK3. The diatom $C y$ clotella choctawatcheeana was the dominant species. Char- 


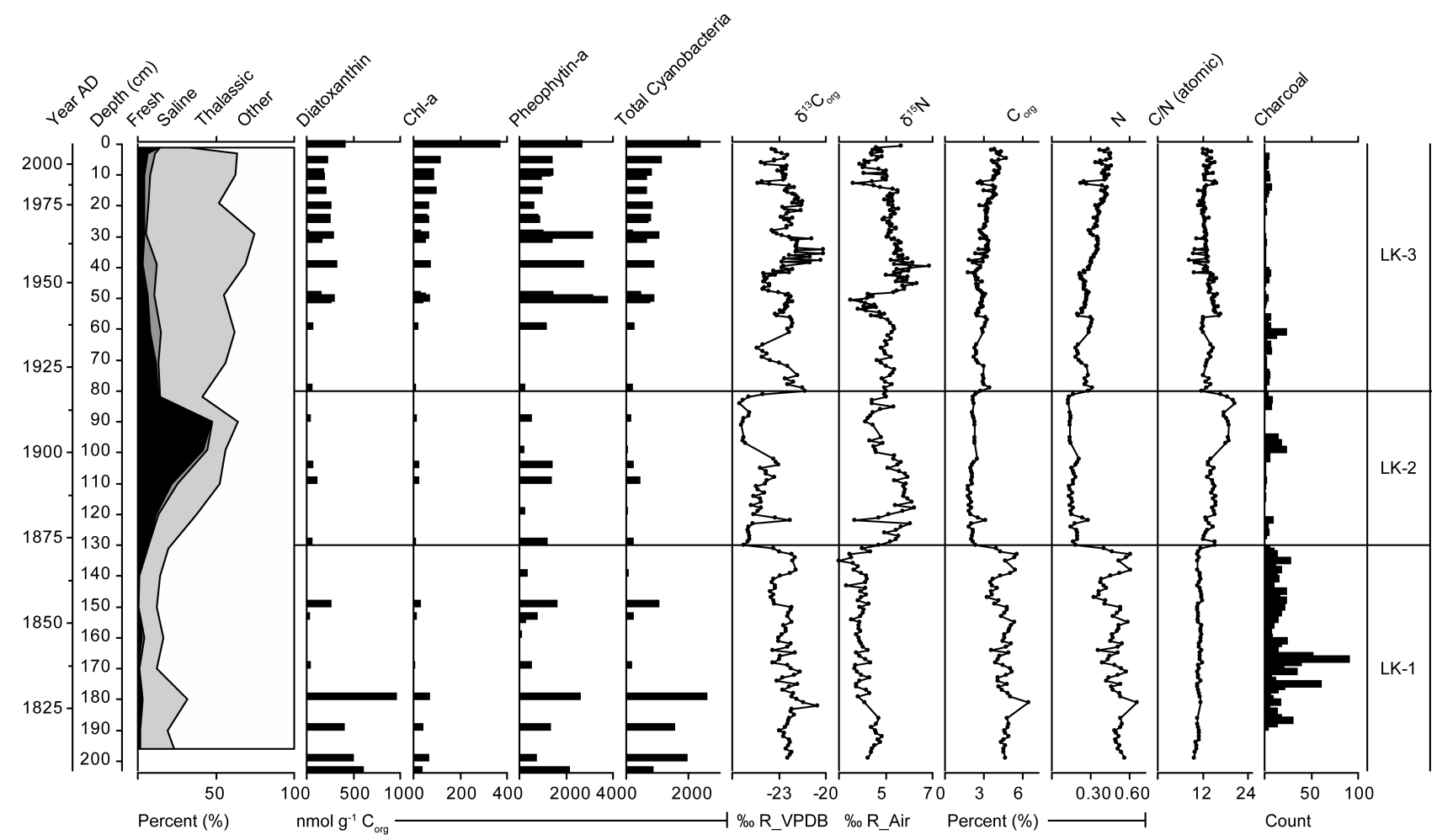

Figure 3. Depth profiles for the site Lake King north of diatom salinity indicator species (See Fig. 4 for classification of species) and geochemical proxies including pigments chlorophyll $a(\mathrm{Chl} a)$, pheophytin $a$ and total cyanobacteria (the sum of the pigments, zeaxanthin, canthaxanthin and echinenone) normalized to sediment organic-carbon content. Sediment organic carbon and nitrogen isotope ratios $\left(\delta^{13} \mathrm{C}\right.$ and $\delta^{15} \mathrm{~N}$ respectively). Sediment organic carbon and total nitrogen content (percentage of sediment mass) and their ratio $\left(\mathrm{C}_{\text {org }}, \mathrm{N}, \mathrm{C} / \mathrm{N}\right.$ respectively). Charcoal content of the sediment expressed in particles per millilitre. The zones LK-1 to LK-3 are three regions of the profile corresponding to inflections in DCA axis 1 (See Fig. 4) and also abrupt changes in the carbon and nitrogen isotope and concentration proxies.

coal abundances were much higher than the subsequent periods and peaked at $170 \mathrm{~cm}$, coinciding with the year $\sim 1825$ (Fig. 4).

\subsubsection{Zone LK2 (c. 1870-1920, depth $130-80 \mathrm{~cm})$}

This zone represents an abrupt change in most proxies and encompasses the period of the opening of the artificial entrance in 1889. The sediment $\delta^{13} \mathrm{C}$, percentage of $\mathrm{C}_{\text {org }}$ and percentage of $\mathrm{N}$ decreased by $1.5 \%, 2$ and $0.2 \%$ respectively at $130 \mathrm{~cm}$ before increasing again by a similar amount at $80 \mathrm{~cm}$. There was also a distinct jump in the $\mathrm{C}_{\text {org }}: \mathrm{N}$ ratio in the sediment from $\sim 11$ to $>13$. Sediment $\delta^{15} \mathrm{~N}$ increased abruptly by $\sim 1 \%$ at the start of the period, but unlike the other proxies it did not show any marked change at the end of this period. There was a distinct peak in the dominance of freshwater diatom species. All pigment markers were relatively low and stable. There was a spike in charcoal at $\sim 100 \mathrm{~cm}$ depth, coinciding with the year $\sim 1900$.

\subsubsection{Zone LK3 (c. 1920-2012, depth 0-80 cm)}

Over this period, percentage of $\mathrm{N}$ and $\mathrm{C}_{\text {org }}$ increased from approximately 0.2 to 0.5 and 2.6 to 4.3 respectively. The $\mathrm{C}_{\text {org }}: \mathrm{N}$ ratio showed an initial decrease and then stabilized at $\sim 11$ (Fig. 3). The $\delta^{13} \mathrm{C}$ and $\delta^{15} \mathrm{~N}$ were relatively constant at -23 and $5 \%$ respectively over the period $1925-1980$ s, and the sedimentation rate was also constant at $1 \mathrm{~cm} \mathrm{yr}^{-1}$. During the late $1980 \mathrm{~s}$, the sedimentation rate slowed from 1 to $0.55 \mathrm{~cm} \mathrm{yr}^{-1}$; at the same time there was a marked decrease in $\delta^{15} \mathrm{~N}, \delta^{13} \mathrm{C}_{\text {org }}$, percentage of $\mathrm{N}$ and percentage of $\mathrm{C}_{\text {org }}$ and a spike in $\mathrm{C}_{\mathrm{org}}: \mathrm{N}$. This change coincided with the first and largest Nodularia spumigena bloom on record in Lake King in 1987, followed by recurring blooms through to the present (Cook and Holland, 2012). In 2006-2007, major bushfires occurred in the east Gippsland catchment, followed by a major flood in 2007.

Concentrations of chlorophyll $a$, diatoxanthin and cyanobacterial pigments increased gradually from 1925 to the late 1980s, before rapidly increasing after this period. Pheophytin $a$ showed sporadic peaks between 1950 and 1975 , before decreasing in the 1980s, followed by another increase after this. Diatoms were dominated by thalassic taxa 


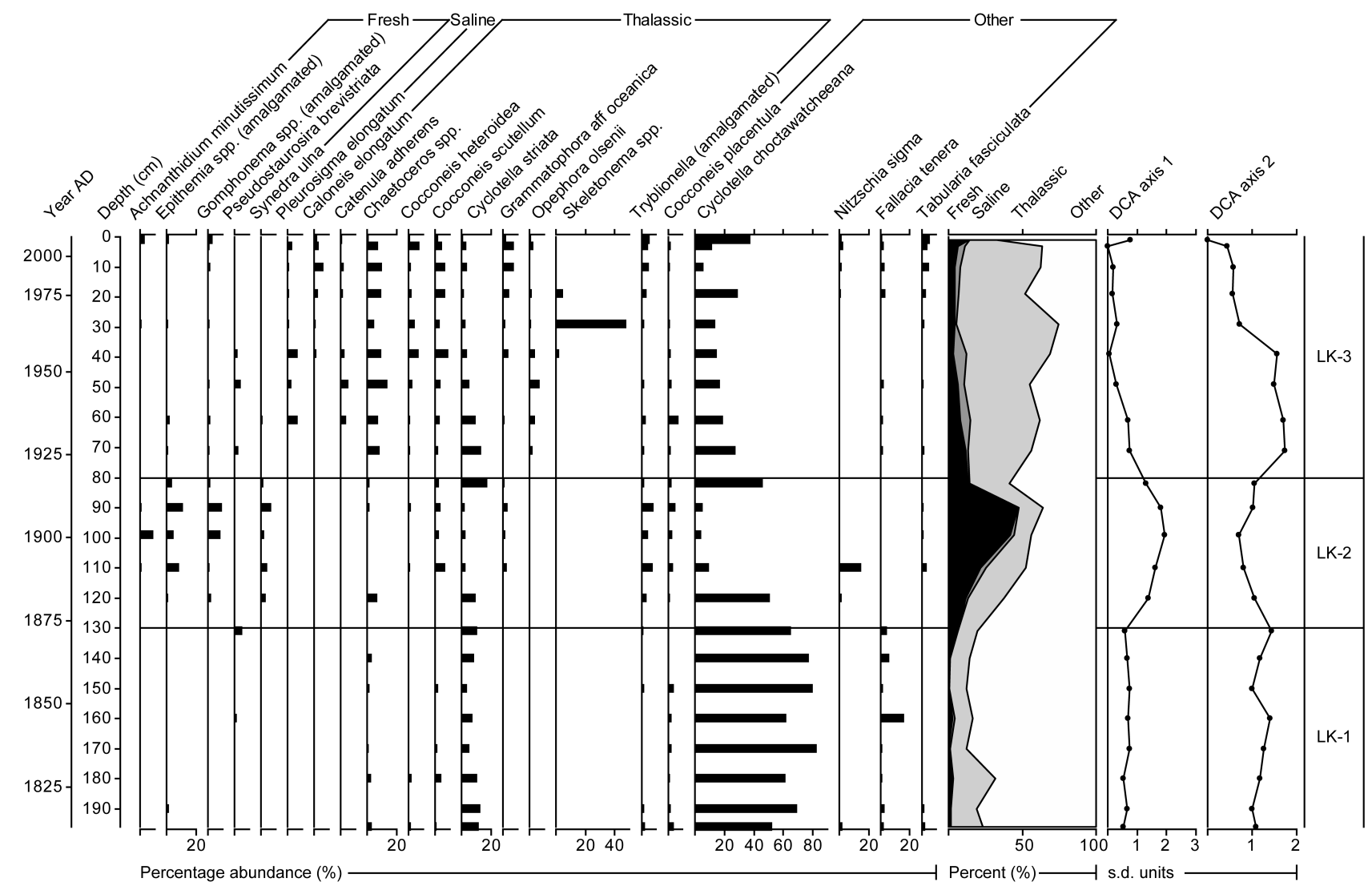

Figure 4. Profiles of diatom species abundance (percentage of total species count) grouped based on water salinity (fresh, saline, thalassic and other). Fresh indicates diatoms found at salinities $<5$, saline indicates species expected to grow at high salinity within estuaries, and thalassic species are expected to be found exclusively in the coastal ocean. Other refers to species typical of intermediate salinity within estuaries and lagoons. Detrended correspondence analysis (DCA) axes 1 and 2 are also shown with depth.

throughout the period 1925 to the present. Charcoal abundance within the sediment was consistently low throughout this period with one spike occurring at $\sim 60 \mathrm{~cm}$ which dates to the period of $\sim 1939$ coincident with some of the most widespread fires on record in the region.

Although there is a possibility of mixing below the depth of ${ }^{210} \mathrm{~Pb}$, we believe that large-scale mixing of the core below this depth can be ruled out, leaving our broad interpretation of the three zones unchanged. First, zone LK-1, which is prior to the opening of the artificial entrance consistently has the highest count of Cyclotella and lowest abundance of thalassic diatoms. Second, many of the proxies measured at high resolution showed abrupt changes throughout the core. If there was significant sediment mixing, such abrupt changes would be smeared out.

\section{Discussion}

\subsection{Impact of settlement}

Prior to European settlement in the early 1840s, land use by the Aboriginal tribes was of a nomadic hunter gathering nature, and documentary evidence suggests that fire was the principal agent of land management across Australia at this time (Gammage, 2011). This account is, however, contradicted by most charcoal records from south-east Australia which show an increased incidence of fire after European settlement (Mooney et al., 2011; Mills et al., 2013). The high charcoal counts below $170 \mathrm{~cm}$ are consistent with high rates of indigenous burning of fringing reedbeds before tubers were harvested, which has been a recognized common practice (Head, 1987). Early European land use was primarily low-intensity sheep grazing. Gold mining commenced in the $1850 \mathrm{~s}$, followed by increased navigation of the lakes in the 1860s for the purposes of trade, fishing and tourism. By the 1870s there was regular steamer traffic on the Mitchell River and there are regular references to dredging the mouths of the Mitchell, Nicholson and Tambo rivers from the early 
1880s through to the turn of the century and into the 1920 s (Synan, 1989). The opening of the permanent entrance in 1889 was one of the pivotal moments in the recent ecological history of the lakes because it led to an increase in the salinity of the Gippsland Lakes (Saunders et al., 2008). Over the period of the opening of the artificial entrance (corresponding to depths of $\sim 110 \mathrm{~cm}$ ), we expected to see a change in the diatom taxa to a greater abundance of thalassic species and a concomitant reduction in freshwater species. Unexpectedly, a spike in freshwater species was instead observed over the period 1870-1925, represented by the LK2 layer. This corresponded to other geochemical proxies which suggested an increase in terrestrial organic matter, including a decrease in $\delta^{13} \mathrm{C}$, and an increase in the sediment $\mathrm{C}: \mathrm{N}$ ratio, which was also observed (although not discussed) by Saunders et al. (2008). This suggests that the study site had an increased influence from riverine sediments over this period. The most likely explanation for this is the remobilization of terrestrial sediments through dredging activities within the delta of the Mitchell River (Fig. 1), which could have led to an increased deposition of terrestrial material at the study site. It appears that this increased input of terrestrial material did not correspond to a changed sedimentation rate as the ${ }^{210} \mathrm{~Pb}$ decay profiles displayed a similar trend between the LK3 and LK2 layers (Fig. 2a). Irrespective of the exact cause of the LK2 sediment layer, we are confident the LK3 and LK1 layers are representative of post and pre artificial entrance opening periods respectively.

\subsection{Cyanobacteria blooms and eutrophication}

The biogeochemical proxies analysed here provide clear evidence for two periods of eutrophication and cyanobacterial blooms in the Gippsland Lakes: (1) the recent period after World War II (LK3) and (2) prior to the opening of the artificial entrance in 1889 (LK1). The latter part of the most recent period has been well monitored and provides an excellent means to validate the biogeochemical proxies. The first piece of evidence for the recent period of eutrophication comes from the steady increase in sediment organic carbon and pheophytin $a$ content after the 1940s (Fig. 3), consistent with a previous palaeolimnological study (Saunders et al., 2008). The $\delta^{13} \mathrm{C}_{\text {org }}$ of this organic matter is typically $\sim-23 \%$, consistent with organic matter inputs derived from phytoplankton (Fig. 3). This period also coincided with a marked jump in the sum of the cyanobacteria pigments zeaxanthin, echinenone and canthaxanthin from $\sim 500 \mathrm{nmol} \mathrm{g}_{\text {org }} \mathrm{C}^{-1}$ up to $>2000 \mathrm{nmol} \mathrm{gorg} \mathrm{\textrm {C } ^ { - 1 }}$ at the top of the core (Fig. 3), consistent with an $N$. spumigena bloom at the site in November 2011-February 2012 (Woodland et al., 2013). The first documented bloom of $N$. spumigena in the lakes occurred in 1965, and the period from 1987 through the 1990s is known to have had severe and regular blooms (Cook and Holland, 2012). Over this period there were also two dips in the $\delta^{15} \mathrm{~N}$ of $\sim 2 \%$ in the 1940 s and late 1980 s-2000, consistent with the occurrence of nitrogen-fixing cyanobacteria. The broad agreement between these cyanobacteria markers and recent recorded blooms gives us confidence that they are appropriate markers of cyanobacteria blooms within the Gippsland Lakes, and this is consistent with previous studies in the Baltic Sea (Bianchi et al., 2000; Funkey et al., 2014).

The biogeochemical proxies for the period prior to the opening of the artificial entrance in 1889 in layer LK1 likewise suggest a period of eutrophication and intense cyanobacteria blooms. The sediment organic content was high $(\sim 5 \%)$, the $\delta^{15} \mathrm{~N}$ was low $\left(\sim 4-5 \%\right.$ ) , the $\delta^{13} \mathrm{C}_{\text {org }}$ was in the range typical of phytoplankton ( -22 to $-23 \%$ ), and the cyanobacteria pigments and pheophytin $a$ were sporadically high (Fig. 3). Reports from newspaper articles in the late 1870 s also suggest the presence of surface scum of cyanobacteria with reference to "noxious and ill smelling weed" on the surface of Lake King and there were anecdotal reports of the greatly improved water quality with the increased salinity after the opening of the artificial entrance in 1889 (Synan, 1989). We now discuss three key factors controlling the incidence of cyanobacteria blooms prior to the opening of the artificial entrance and European settlement.

1. Salinity. With no permanent entrance, the inflow of seawater was greatly reduced, and at this time the lakes were considerably fresher (Harris et al., 1988; Saunders et al., 2008). The diatom chronology also supports this reduced marine influence with an increased abundance of Cyclotella choctawatcheeana, a planktonic diatom characteristic of deep mesosaline (salinities $>10$ ) lakes and brackish marine systems (Fritz et al., 1993), and the reduced dominance of thalassic diatoms (Fig. 4). $N$. spumigena typically blooms at salinities between 9 and 20 in the Gippsland Lakes, and these salinities are currently only reached during late spring-summer in highflow years (Cook and Holland, 2012). Prior to the opening of the artificial entrance, it is likely that this salinity range was more typical, hence increasing the frequency of blooms. In high-flow years when salinities were even lower, it is likely that other nitrogen-fixing cyanobacteria, such as Anabaena would instead dominate. This species occasionally blooms in Lake Wellington, and it is therefore possible that this cyanobacterium was present in Lake King prior to 1889.

2. Stratification and residence time. At present, the highest stratification is observed during periods of low surface water salinity in the Gippsland Lakes associated with above-average river flows (Cook and Holland, 2012). Reduced tidal flushing, combined with low surface salinity, would lead to enhanced stratification and residence time of the water column, which are both known to favour buoyant slow-growing cyanobacteria such as N. spumigena (Sellner, 1997; Paerl, 2014). Increased stratification will also lead to increased hypoxia, and the marked increase in sediment organic-carbon content to 
$\sim 5 \%$ prior to $\sim 1870$ (below $130 \mathrm{~cm}$, Fig. 4 ) is consistent with increased hypoxia in this period (Zillen and Conley, 2010). A key effect of this would be to enhance the release of phosphorus from the sediment, which is a key driver of $N$. spumigena blooms in the Gippsland Lakes (Cook et al., 2010; Scicluna et al., 2015).

3. Nutrients. Prior to European settlement, it has been estimated that nitrogen and phosphorus loads were lower by a factor of 2 and 3 respectively (Grayson et al., 2001). At face value, it is surprising that the Gippsland Lakes experienced more blooms of cyanobacteria then; however, this can be reconciled with contemporary studies. First, cyanobacteria such as $N$. spumigena can derive all of their nitrogen requirements from nitrogen fixation, and these blooms can add significant loads to the Gippsland Lakes (Woodland and Cook, 2014). The generally lower sediment $\delta^{15} \mathrm{~N}$ values prior to 1870 (below $130 \mathrm{~cm}$ ) are consistent with this. Second, cyanobacterial blooms are driven by a focused release of phosphorus from the sediments during bottom water hypoxia or anoxia, and it was estimated that a large recent bloom of $N$. spumigena was caused by a release of $\sim 25 \mathrm{t}$ of phosphorus from the sediment in Lake King (Scicluna et al., 2015). Given that phosphorus is trapped and effectively recycled in periodically anoxic and high residence time systems such as the Gippsland Lakes, it is plausible that a pre-European phosphorus catchment load of $50 \mathrm{t}$ per year could maintain blooms of at least the same magnitude as currently observed (Grayson et al., 2001).

\subsection{Did nitrogen play a key role in the re-emergence of cyanobacteria blooms?}

Following the opening of the artificial entrance there was a $\sim 60$-year period $(\sim 80-130 \mathrm{~cm})$ with relatively low cyanobacteria biomass and oxic bottom water, as indicated by the reduction in cyanobacteria pigments and sediment organic-carbon content respectively. It is likely that this relatively low-productivity period was caused by relatively good ventilation of the bottom water combined with low catchment nutrient inputs. After the 1940s, the modern eutrophication of the Gippsland Lakes commenced, as indicated by a steady increase in sediment organic carbon and cyanobacteria pigments. Changes to hydrological, morphological and salinity regimes are unlikely to be a key driver because, apart from a $20 \%$ reduction in river inputs from river diversions (Moroka, 2010), there have been no significant hydrological and morphological changes to the Gippsland Lakes over this period. Given that fire can lead to increased nutrient loads as previously discussed, it is highly likely that the 1939 wildfires (Australian Broadcasting Corporation, 2016) led to a significant pulse of nutrients into the Gippsland Lakes. The subsequent increase in agriculture (Lake Glenmaggie, used for irrigation in the Macalister Irrigation District, a tributary of the Latrobe River, was completed in 1926 and expanded immediately post World War II), industry and urbanization within the catchment have been estimated to have increased nutrient loads by a factor of 1.8 and 3 for total nitrogen and phosphorus respectively (Grayson et al., 2001).

Previous work has shown that the Gippsland Lakes are generally nitrogen limited outside $N$. spumigena blooms (Holland et al., 2012), and increased inputs of this element have most likely resulted in increased productivity in the Gippsland Lakes, particularly during the winter and spring diatom blooms when most of the nutrient load is delivered. The increased settling of phytodetritus after the collapse of these blooms would have driven increased water column anoxia over the late-spring period, triggering the release of phosphorus stored in the sediment leading to more favourable conditions for $N$. spumigena blooms (Cook et al., 2010; Scicluna et al., 2015; Holland et al., 2012). We therefore speculate that the recent re-emergence of cyanobacterial blooms is amplified by increased nitrogen loads, which drive an increased internal release of phosphorus through increased bottom water hypoxia and anoxia in late spring through to summer. These observations are consistent with global studies of coastal waters, which consistently show an increased incidence of hypoxia over the past 50 years driven by eutrophication (Diaz and Rosenberg, 2008) and that this may then lead on to blooms of cyanobacteria (Funkey et al., 2014). This finding supports the argument that mitigating coastal eutrophication requires controls on both nitrogen and phosphorus (Paerl, 2014; Conley et al., 2009), even in systems that experience diazotrophic cyanobacterial blooms.

\section{Conclusions}

In conclusion, blooms of cyanobacteria were a natural feature of the Gippsland Lakes prior to European settlement, most likely driven by strong stratification and phosphorus release from the sediment. We suggest that pre-European phosphorus loads were sufficient to maintain a sediment phosphorus pool capable of driving significant periodic blooms based on contemporary observations. The opening of the artificial entrance in 1889 likely led to increased salinity, flushing and reduced stratification, leading to an increase in bottom water oxygenation, a decrease in sediment phosphorus release and associated cyanobacterial blooms. The re-emergence of cyanobacterial blooms post World War II may have occurred as a consequence of increased nitrogen inputs, which led to increased anoxia occurring as a consequence of increased primary production, triggering sediment phosphorus release during the summer low-flow period when blooms occur. This finding provides a mechanism by which decreasing nitrogen loads may also reduce phosphorus-limited diazotrophic cyanobacterial blooms by reducing phosphorus release from the sediment, highlighting the need to control both nitrogen 
and phosphorus loads to estuaries even when they experience blooms of diazotrophic cyanobacteria.

Author contributions. Perran L. M. Cook conceived of and coordinated the work and led the writing of the manuscript. Miles Jennings collected the cores, processed them for dating and undertook the stable isotope analysis, which formed his honours thesis. Daryl P. Holland and John Beardall assisted with the writing of the manuscript and coordination of the work. Christy Briles undertook the charcoal counts and assisted with the writing of the manuscript. Atun Zawadzki undertook the core dating analyses and contributed to writing the manuscript. Phuong Doan undertook pigment analyses and contributed to the writing of the manuscript. Keely Mills assisted with core sampling, data processing and interpretation, and the writing of the manuscript. Peter Gell undertook diatom identification and counts and the writing of the manuscript.

Acknowledgements. This work was supported by the Australian Research Council (LP110100040), the Australian Institute of Nuclear Science and Engineering (ALNGRA12139), the Gippsland Lakes Ministerial Advisory Committee, EPA Victoria and Melbourne Water. We thank V. Evrard and K. Browne for undertaking the isotope analyses. Keely Mills publishes with the approval of the Executive Director, British Geological Survey (NERC).

Edited by: S. Pantoja

\section{References}

Appleby, P.: Chronostratigraphic techniques in recent sediments, in: Tracking environmental change using lake sediments, Vol 1: Basin analysis, coring and chronological techniques, edited by: Last, W. and Smol, J., Kluwer Academic Publishers, Dordrecht, 2001

Atahan, P., Heijnis, H., Dodson, J., Grice, K., Le Metayer, P., Taffs, K., Hembrow, S., Woltering, M., and Zawadzki, A.: Pollen, biomarker and stable isotope evidence of late Quaternary environmental change at Lake McKenzie, southeast Queensland, J. Paleolimnol., 53, 139-156, doi:10.1007/s10933-014-9813-3, 2015.

Battarbee, R. W.: Diatom Analysis, in: Handbook of Holocene Palaeoecology and Palaeohydrology, edited by: Berglund, B. E., John Wiley \& Sons., Chichester, 1986.

Bianchi, T. S., Engelhaupt, E., Westman, P., Andren, T., Rolff, C., and Elmgren, R.: Cyanobacterial blooms in the Baltic Sea: Natural or human-induced?, Limnol. Oceanogr., 45, 716-726, 2000.

Bird, E. C. F.: The geomorphology of the Gippsland Lakes region Ministry for Conservation, Victoria, 158 pp., 1978.

Chen, N., Bianchi, T., McKee, B., and Bland, J.: Historical trends of hypoxia on the Louisiana shelf: Application of pigments as biomarkers, Org. Geochem., 32, 543-561, 2001.

Conley, D. J., Paerl, H. W., Howarth, R. W., Boesch, D. F., Seitzinger, S. P., Havens, K. E., Lancelot, C., and Likens, G. E.: ECOLOGY Controlling Eutrophication: Nitrogen and Phosphorus, Science, 323, 1014-1015, doi:10.1126/science.1167755, 2009.
Cook, P. L. M. and Holland, D. P.: Long term nutrient loads and phytoplankton dynamics in a large temperate Australian lagoon system affected by recurring blooms of Nodularia spumigena, Biogeochemistry, 107, 261-274, 2012.

Cook, P. L. M., Holland, D. P., and Longmore, A. R.: Effect of a flood event on the dynamics of phytoplankton and biogeochemistry in a large temperate Australian lagoon, Limnol. Oceanogr., 55, 1123-1133, 2010.

Diaz, R. J. and Rosenberg, R.: Spreading dead zones and consequences for marine ecosystems, Science, 321, 926-929, 2008.

Foged, N.: Diatoms in eastern Australia, Bibliotheca Phycologica Series No. 41, Lubrecht \& Cramer Ltd, 1978.

Fritz, S. C., Juggins, S., and Battarbee, R. W.: Diatom assemblages and ionic characterization of lakes of the Northern Great Plains, North America: A tool for reconstructing past salinity and climate fluctuations, Can. J. Fish. Aquat. Sci., 50, 1844-1856, 1993.

Funkey, C. P., Conley, D. J., Reuss, N. S., Humborg, C., Jilbert, T., and Slomp, C. P.: Hypoxia Sustains Cyanobacteria Blooms in the Baltic Sea, Environ. Sci. Technol., 48, 2598-2602, doi:10.1021/es404395a, 2014.

Gammage, W.: The Largest Estate on Earth: How Aborigines Made Australia, Allen and Unwin, Sydney, 434 pp., 2011.

Grayson, R. B., Tan, K. S., and Wealands, S.: Pre-European load estimates into the Gippsland Lakes, University of Melbourne, 5, 2001.

Harris, G., Batley, G., Webster, I. T., Molloy, R., and Fox, D.: Gippsland Lakes Environmental Audit: Review of water quality and status of the aquatic ecosystems of the Gippsland Lakes, CSIRO, Melbourne, 1988.

Head, L.: The Holocene prehistory of a coastal wetland system: Discovery bay, southeastern Australia, Human Ecol., 15, 435-462, 1987.

Holland, D. P., Van Erp, I. C., Beardall, J., and Cook, P. L. M.: Environmental controls on the growth of the nitrogen-fixing cyanobacterium Nodularia spumigena Mertens in a temperate lagoon system in South-Eastern Australia, Mar. Ecol.-Prog. Ser., 461, 47-57, 2012.

Jeffrey, S. W. and Vesk, M.: Introduction to marine phytoplankton and their pigment signatures, in: Phytoplankton Pigments in Oceanography: Guidlines to Modern Methods, edited by: Jeffrey, S. W., Mantoura, R. F. C., and Wright, S. W., UNESCO Publishing, Paris, 37-84, 1997.

Juggins, S.: C2 user Guide: Software for Ecological and Palaeoecological Data Analysis and Visualisation, University of Newcastle, Newcastle upon Tyne, United Kingdom, 2003.

Krammer, K. and Lange-Bertalot, H.: Bacillariophyceae, 1. Teil, Naviculaceae, Süßwasserflora von Mitteleuropa, Band 2/1, Spektrum Akademischer Verlag, Stuttgart, 1986.

Krammer, K. and Lange-Bertalot, H.: Bacillariophyceae, 2. Teil, Bacillariaceae, Epithemiaceae, Surirellaceae, Süßwasserflora von Mitteleuropa, Band 2/2, Spektrum Akademischer Verlag, Stuttgart, 1988.

Krammer, K. and Lange-Bertalot, H.: Bacillariophyceae, 4. Teil, Achnanthaceae, kritsche erganzungen zu Navicula (Lineolatae) und Gomphonema Gesamliteraturverzeichnis, Süßwasserflora von Mitteleuropa, Band 2/4, Spektrum Akademischer Verlag, Stuttgart, 1991a. 
Krammer, K. and Lange-Bertalot, H.: Bacillariophyceae, 3. Teil, Centrales, Fragilariaceae, Eunotiaceae, Süßwasserflora von Mitteleuropa, Band 2/3, Spektrum Akademischer Verlag, Stuttgart, $1991 b$.

Leslie, C. and Hancock, G.: Estimatin the date corresponding to the horizon of the first detection of ${ }^{137} \mathrm{Cs}$ and ${ }^{239+240} \mathrm{Pu}$ in sediment cores, J. Environ. Radioactiv., 99, 483-490, 2008.

Lukatelich, R. J. and McComb, A. J.: Nutrient levels and the development of diatom and blue-green-algal blooms in a shallow Australian estuary, J. Plankton Res., 8, 597-618, 1986.

Mantoura, R. F. C. and Llewellyn, C. A.: The rapid determination of algal chlorophyll and carotenoid pigments and their breakdown products in natural waters by reverse-phase highperformance liquid chromatography, Anal. Chim. Ac., 151, 297314, doi:10.1016/S0003-2670(00)80092-6, 1983.

McComb, A. J. and Humphries, R.: Loss of nutrients from catchments and their ecological impacts in the Peel-Harvey estuarine system, Western Australia, Estuaries, 15, 529-537, 1992.

Mills, K., Gell, P., Gergis, J., Baker, P. J., Finlayson, C. M., Hesse, P. P., Jones, R., Kershaw, P., Pearson, S., Treble, P. C., Barr, C., Brookhouse, M., Drysdale, R., McDonald, J., Haberle, S., Reid, M., Thoms, M., and Tibby, J.: Paleoclimate studies and naturalresource management in the Murray-Darling Basin II, Unravelling human impacts and climate variability, Aust. J. Earth Sci., 60, 561-571, 2013.

Mooney, S. D., Harrison, S. P., Bertlein, P. J., Daniau, A.-L., Stevenson, J., Brownlie, K. C., Buckman, S., Cupper, M., luly, J., Black, M., Colhoun, E., D’Costa, D., Dodson, J., Haberle, S., Hope, G. S., Kershaw, P., Kenyon, C., Mckenzie, M., and Williams, N.: Late Quaternary fire regimes of Australasia, Quaternary Sci. Rev., 30, 28-46, 2011.

Moroka Consulting: Understanding the Environmental Water Requirements of the Gippsland Lakes Systems, Stage 2: Input to the Gippsland region Sustainable Water Strategy, Report to East and West Gippsland Catchment Management Authorities, Traralgon, Moroka, Melbourne, 2010.

Paerl, H. W.: Mitigating Harmful Cyanobacterial Blooms in a Human- and Climatically-Impacted World, Life, 4, 988-1012, doi:10.3390/life4040988, 2014.
Paerl, H. W. and Paul, V. J.: Climate change: Links to global expansion of harmful cyanobacteria, Water Res., 46, 1349-1363, doi:10.1016/j.watres.2011.08.002, 2012.

Saunders, K. M., Hodgson, D. A., Harrison, J., and McMinn, A.: Palaeoecological tools for improving the management of coastal ecosystems: a case study from Lake King (Gippsland Lakes) Australia, J. Paleolimnol., 40, 33-47, doi:10.1007/s10933-0079132-z, 2008.

Scicluna, T. R., Woodland, R. J., Zhu, Y., Grace, M. R., and Cook, P. L. M.: Deep dynamic pools of phosphorus in the sediment of a temperate lagoon with recurring blooms of diazotrophic cyanobacteria, Limnol. Oceanogr., 60, 2185-2196, 2015.

Sellner, K. G.: Physiology, ecology, and toxic properties of marine cyanobacteria blooms, Limnol. Oceanogr., 42, 1089-1104, 1997.

Sonneman, J. A., Sincock, A., Fluin, J., Reid, M., Newall, P., Tibby, J., and Gell, P.: An illustrated guide to common stream diatom species from temperate Australia, Cooperative Research Centre for Freshwater Ecology Identification Guide No. 33., 2000.

Synan, P.: The Lakes: Highways of Water, Landmark Press, Drouin, 235 pp., 1989.

Wildsmith, M. D., Rose, T. H., Potter, I. C., Warwick, R. M., Clarke, K. R., and Valesini, F. J.: Changes in the benthic macroinvertebrate fauna of a large microtidal estuary following extreme modifications aimed at reducing eutrophication, Mar. Pollut. Bull., 58, 1250-1262, doi:10.1016/j.marpolbul.2009.06.008, 2009.

Woodland, R. J. and Cook, P. L. M.: Using stable isotope ratios to estimate atmospheric nitrogen fixed by cyanobacteria at the ecosystem-scale, Ecol. Appl., 24, 539-547, doi:10.1890/130947.1, 2014.

Woodland, R. J., Holland, D. P., Beardall, J., Smith, J., Scicluna, T. R., and Cook, P. L. M.: Assimilation of Diazotrophic nitrogen into food webs, Plos ONE, 8, e67588, doi:10.1371/journal.pone.0067588, 2013.

Zillén, L. and Conley, D. J.: Hypoxia and cyanobacteria blooms are they really natural features of the late Holocene history of the Baltic Sea?, Biogeosciences, 7, 2567-2580, doi:10.5194/bg7-2567-2010, 2010. 